\title{
Genomic landscape and its correlations with tumor mutational burden, PD-L1 expression, and immune cells infiltration in Chinese lung squamous cell carcinoma
}

Tao Jiang ${ }^{1+}$, Jinpeng Shi ${ }^{1+}$, Zhengwei Dong ${ }^{2}$, Likun Hou ${ }^{2}$, Chao Zhao ${ }^{3}$, Xuefei Li $i^{3}$, Beibei Mao ${ }^{4}$, Wei Zhu ${ }^{4}$, Xianchao Guo ${ }^{4}$, Henghui Zhang ${ }^{4}, \mathrm{Ji} \mathrm{He}^{4}$, Xiaoxia Chen ${ }^{1}$, Chunxia Su', Shengxiang Ren ${ }^{1}$, Chunyan $\mathrm{Wu}^{2^{*}}$ and Caicun Zhou ${ }^{1 *}$

\begin{abstract}
Introduction: To depict the genomic landscape of Chinese early-stage lung squamous cell carcinoma (LUSC) and investigate its correlation with tumor mutation burden (TMB), PD-L1 expression, and immune infiltrates.

Methods: Whole-exome sequencing was performed on 189 surgically resected LUSC. TMB was defined as the sum of nonsynonymous single nucleotide and indel variants. CD8 ${ }^{+}$tumor-infiltrating lymphocyte (TIL) density and PD-L1 expression were evaluated by immunohistochemistry. Six immune infiltrates were estimated using an online database.

Results: The median TMB was 9.43 mutations per megabase. Positive PD-L1 expression and CD8 ${ }^{+}$TILs density were identified in $24.3 \%$ and $78.8 \%$. PIK3CA amplification was associated with significantly higher TMB $(P=0.036)$. Frequent genetic alterations had no impact on PD-L1 expression but PIK3CA amplification and KEAP1 mutation were independently associated with significantly lower CD8 $8^{+}$TIL density $(P<0.001, P=0.005$, respectively). Low $\mathrm{TMB}$ and high $\mathrm{CD} 8^{+}$TIL density were independently associated with longer disease-free survival (DFS) while none of them could individually predict the overall survival (OS). Combination of TMB and PD-L1 expression or $\mathrm{TMB}$ and $\mathrm{CD}^{+}{ }^{+} \mathrm{TIL}$ density could stratify total populations into two groups with distinct prognosis. Classifying tumor-immune microenvironment based on PD-L1 expression and CD8 ${ }^{+}$TIL density showed discrepant genomic alterations but similar TMB, clinical features, and OS. Notably, patients with different smoking status had distinct prognostic factors.
\end{abstract}

Conclusion: The combination of TMB, PD-L1 expression, immune infiltrates, and smoking status showed the feasibility to subgroup stratification in Chinese patients with early-stage LUSC, which might be helpful for future design of personalized immunotherapy trials in LUSC.

Keywords: Lung squamous cell carcinoma, Genome, TMB, PD-L1, Immune cells

\footnotetext{
*Correspondence: wuchunyan581@sina.com; caicunzhou_dr@163.com

${ }^{\dagger}$ Chunyan Wu and Caicun Zhou contributed equally to this paper.

${ }^{2}$ Department of Pathology, Shanghai Pulmonary Hospital \& Thoracic Cancer

Institute, Tongji University School of Medicine, Shanghai 200433, China

'Department of Medical Oncology, Shanghai Pulmonary Hospital \& Thoracic

Cancer Institute, Tongji University School of Medicine, Zheng Min Road,

Shanghai 200433, China

Full list of author information is available at the end of the article
}

(c) The Author(s). 2019 Open Access This article is distributed under the terms of the Creative Commons Attribution 4.0 International License (http://creativecommons.org/licenses/by/4.0/), which permits unrestricted use, distribution, and reproduction in any medium, provided you give appropriate credit to the original author(s) and the source, provide a link to the Creative Commons license, and indicate if changes were made. The Creative Commons Public Domain Dedication waiver (http://creativecommons.org/publicdomain/zero/1.0/) applies to the data made available in this article, unless otherwise stated. 


\section{Introduction}

Lung squamous cell carcinoma (LUSC) is one of the most common histological subtypes of non-small-cell lung cancer (NSCLC), the remaining leading cause of cancerrelated death worldwide for a long period [1-3]. Unlike lung adenocarcinoma (LUAD) with oncogenic driver alterations, therapeutic progress for LUSC is limited and conventional platinum-based chemotherapy remains the standard-of-care for many years [4-6]. Recently, immune checkpoint inhibitors targeted programmed cell death 1 (PD-1) and its ligand (PD-L1) has a shift the paradigm in both LUAD and LUSC. To date, several anti-PD-1/PD-L1 antibodies including nivolumab, pembrolizumab, and atezolizumab have been approved as second-line settings for patients with advanced NSCLC [7-11]. Moreover, pembrolizumab monotherapy showed superiority as a first-line setting when compared with chemotherapy in patients with PD-L1 tumor proportion score (TPS) $>1 \%$, and pembrolizumab plus platinum-based chemotherapy become the standard-of-care for first-line setting patients with LUSC $[11,12]$. Emerging evidence indicated that positive PD-L1 expression and high tumor mutation burden (TMB) could predict the response to anti-PD-1/PD-L1 therapies in NSCLC $[12,13]$. However, the ideal predictive biomarkers for immunotherapy are still an unmet need in clinical practice. Inspiringly, latest reports found gene profiling showed the potent to predict response to immune checkpoint inhibitors [14-16].

For patients with early-stage LUSC, curative surgery with adjuvant chemotherapy is the main therapeutic option even though adjuvant chemotherapy just brought limited survival benefit [17]. Recently, neoadjuvant and adjuvant immune checkpoint inhibitors showed promising results in this setting. A pilot study found that neoadjuvant nivolumab resulted in a major pathological response of 45\% [18]. Further biomarker analysis found that TMB was predictive of the pathological response to neoadjuvant nivolumab, while in LCMC3 study, TMB did not associate with pathological response for neoadjuvant atezolizumab and response was found in patients with PD-L1 expression negative [19]. Therefore, comprehensively depicting the genomic and immune landscape, their correlations are needed to elucidate the ideal phenotype to benefit neo-adjuvant immunotherapy in patients with early-stage NSCLC. Although several studies have reported the relevant data on LUAD $[20,21]$, the situation in LUSC is still largely unknown.

Herein, we performed this study in 189 Chinese patients with early-stage LUSC to evaluate (1) the genomic landscape of LUSC and its correlation with PD-L1 expression, TMB, and six immune infiltrates and (2) their associations with clinical parameters, disease-free survival (DFS), and overall survival (OS). Additionally, we also compared our data to other ethnicities and tumor types such as adenocarcinoma.

\section{Methods}

\section{Sample collection}

We retrospectively identified patients who underwent surgical resection of the lung (lobectomy or pulmonectomy) and histologically confirmed LUSC at Shanghai Pulmonary Hospital from 2012 to 2015 . We firstly checked the histological types of each case using medical electronic records. Then all primary diagnoses were further independently evaluated by two experienced pathologists (Z.W.D and L.K.H) according to the WHO nomenclature for squamous carcinoma. The specimens of eligible case must have a confirmed diagnosis of LUSC and had at least 50\% tumor cellularity. Major exclusion criteria were inadequate or poor quality samples, missing baseline clinicopathological features, mixed histology, and incomplete follow-up data. Corresponding formalin-fixed and paraffin-embedded (FFPE) tissues were used for immunohistochemistry (IHC) staining and whole-exome sequencing. The major baseline features including age, sex, smoking history, Eastern Cooperative Oncology Group performance status (ECOG PS), tumor size, node status and stage, vascular invasion, differentiation degree, tumor stage, DFS, and OS. A never-smoker was defined as a patient who had smoked less than 100 cigarettes during his/her lifetime. DFS was defined as the time from the initial surgical resection until recurrence. OS was calculated from the date of LUSC diagnosis to death from any cause or was censored at the last follow-up date. This study was conducted in accordance with the provisions of the Declaration of Helsinki and was approved by the ethics committee of Shanghai Pulmonary Hospital.

\section{PD-L1 expression}

PD-L1 expression was firstly tested by using anti-human PD-L1 (\#13684, clone E1L3N, Cell Signaling Technology, Danvers, MA, diluted 1:200) according to the manufacturer's recommendations and previous publications using 4-5 $\mu \mathrm{m}$ FFPE sections [22, 23]. Then all of the samples were re-evaluated by using another antibody assay (clone SP142, Spring Bioscience, Ventana, Tucson, AZ, diluted 1:100) [24]. For E1L3N staining, PD-L1 expression was defined as the percentage of tumor cells showing membranous immunoreactivity (central or marginal tumor region). The cutoff value was $5 \%$ for PD-L1 positivity or negativity (PD-L1 $1^{+/-}$). PD-L1 $>50 \%$ was defined as PD-L1 strong positivity. For SP142 staining, positive cells were defined as cancer cells displaying membranous staining for PD-L1, and the proportion of PD- $\mathrm{L}^{+}$cells was evaluated as the percentage of total cancer cells in whole sections. The cutoff values of $1 \%$, $5 \%, 10 \%$, and $50 \%$ were set and $1 \%$ was determined for PD-L1 ${ }^{+/-}[25,26]$. Sections from human placenta tissues were used as the positive controls of PD-L1 IHC 
staining. Breast cancer cell line (MCF-7) was utilized as the negative control. All of the stained sections were independently reviewed by two pathologists (Z.W.D and L.K.H). Any discrepancies were discussed together and a consensus was achieved under the guidance of another experienced pathologist (C.Y.W).

\section{$\mathrm{CD}^{+}$tumor-infiltrating lymphocyte (TIL) density}

$\mathrm{CD} 8^{+}$TILs density was assessed by using a mouse antiCD8 monoclonal antibody (M7103, clone C8144B, DAKO) . Lymphocytes with immunostained CD8 infiltrating within a tumor region (central or marginal) were defined as $\mathrm{CD} 8^{+}$ TILs. On the basis of the percentage of $\mathrm{CD}^{+}$TILs displayed within a tumor region, we determined high/low $\mathrm{CD} 8^{+}$TIL density $\left(\mathrm{CD}^{+} \mathrm{TIL}^{+/-}\right)$with a cutoff of $5 \%$, which was analogous to the previous studies $[23,27]$.

\section{TMB calculation}

The details of whole-exome sequencing and data processing were listed in Additional file 1. TMB was defined as the number of somatic, coding, base substitution, and indel mutations per megabase of genome examined by using nonsynonymous and frameshift indels at 5\% limit of detection. Variants in low confidence regions and repeat regions, driver mutations and germline mutations were removed via using population online databases (The Exome Aggregation Consortium v.03, Genome Aggregation Database, and 1000 Genome) followed by variant allelic frequency cutoff of $0.2 \%$. The tumor mutation calculation formula was as follows:

$$
\mathrm{TMB}=\frac{S_{n} \times 1000000}{N}
$$

$S_{n}$ represents the absolute number of somatic mutations, and $N$ represents the number of exonic bases coverage depth $\geq 100 \times$.

\section{Estimation of immune cells infiltration}

The abundances of six immune cell infiltrations including $\mathrm{B}$ cells, $\mathrm{CD} 4^{+} \mathrm{T}$ cells, $\mathrm{CD} 8^{+} \mathrm{T}$ cells, macrophages, neutrophils, and dendritic cells (DC) in specific groups of LUSC were estimated by using online database, named Tumor Immune Estimation Resource (TIMER). TIMER is a comprehensive resource for systematical analysis of immune cell infiltrations across diverse cancer types, which is validated using pathological estimations. The details and statistical methods were listed in this website (https:// cistrome.shinyapps.io/timer/) and their previous publications $[28,29]$.

\section{Statistical analysis}

The Pearson correlation coefficient was used to determine the correlation of PD-L1 expression level between two antibody assays. Spearman's rank correlation was utilized to assess the correlations among PD-L1 expression, $\mathrm{TMB}$, and $\mathrm{CD} 8^{+} \mathrm{TIL}$ density. Correlations between PD-L1 expression/CD8 ${ }^{+}$TIL density and clinical parameters were analyzed using the chi-squared or Fisher's exact test for categorical variables. The continuous variable was analyzed by ANOVA and Tukey's multiple comparison tests. Mann-Whitney $U$ tests or KruskalWallis rank sum tests were used for comparisons of continuous variables across multiple groups. The KaplanMeier curve was leveraged to assess the patients' survival curves. The log-rank test was used to test the significance of differences between two or four groups. Cox proportional hazards model was utilized for uni- and multivariate survival analyses to calculate the hazard ratios (HR) and related $95 \%$ confidence intervals $(\mathrm{CI}) . P<0.05$ was considered significant. All statistical analyses were performed using GraphPad PRISM 6.0 and the SPSS statistical software, version 22.0 (SPSS Inc., Chicago, IL, USA).

\section{Results}

Genomic landscape of Chinese LUSC and its correlations with TMB, PD-L1 expression, or immune cells infiltration One hundred eighty-nine samples were successfully sequenced. The baseline characteristics were listed in Table 1 . The median age was 63 years (range $36-80$ years). One hundred seventy-nine $(94.7 \%)$ patients were male. The percentage of never-smokers (31.7\%) was higher than those in previous studies $[30,31]$. Ninety-two $(48.7 \%)$ patients had pathological stage I disease and most of them had PS $0-1$. The mean sequencing coverage across all regions was $101 \times$ with $96.4 \%$ of targeted bases above $20 \times$ coverage. We identified eight genes with a somatic mutation frequency $>5 \%$ of all cases (Fig. 1a): TP53, KMT2C, NFE2L2, KEAP1, CDKN2A, PTEN, FBXW7, and PIK3CA. This would have a slight difference to TCGA which identified 10 genes (TP53, CDKN2A, PTEN, PIK3CA, KEAP1, MLL2, HLA-A, NFE2L2, NOTCH1, and RB1) with a false discovery rate (FDR) $Q$ value $<0.1$ [30]. In Caucasian with LUSC (Choi et al. cohort), 14 genes exhibited significant enrichment for somatic mutation: TP53, MLL2, PIK3CA, NFE2L2, CDH8, KEAP1, PTEN, ADCY8, PTPRT, CALCR, GRM8, FBXW7, RB1, and CDKN2A [19]. TP53 mutation was found in $67 \%$ of all cases (TCGA, $81 \%$; Choi et al. cohort, $60 \%$ ). There were 10 genes with significant copy number variations (CNVs; Fig. 1b): EGFR, PIK3CA, FGFR1, CCND1, CDKN2A, SOX2, PDGFRA, PTEN, MET, and FGFR2. EGFR amplification (32\%) was the most frequent. PIK3CA and FGFR1 amplifications were found in $23 \%$ and $20 \%$ of all cases, respectively. Interestingly, we found a high frequency of $E M L 4-A L K$ fusion (3.2\%), one of the most common driver gene alterations in LUAD. There was no significant correlation between EGFR 
Table 1 Baseline characteristics of included patients $(n=189)$

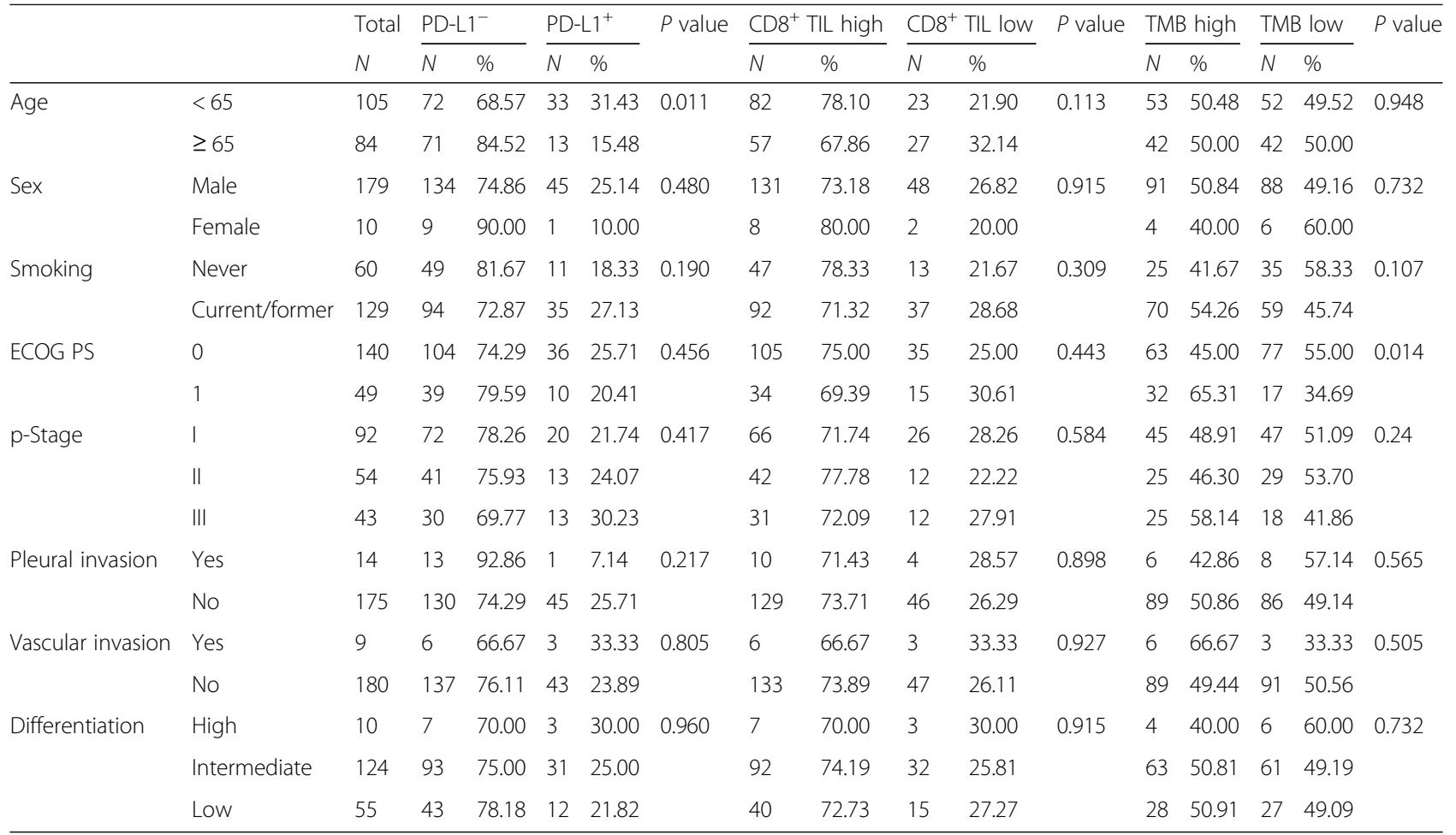

ECOG PS Eastern Cooperative Oncology Group performance score, $p$ pathological, PD-L1 programmed death ligand 1, TIL tumor-infiltrating lymphocyte, TMB tumor mutation burden

amplification or EML4-ALK fusion and clinicopathological features (Additional file 1: Table S1).

The mean TMB was 10.77 mutations per megabase (mut/Mb) and median TMB was 9.43 mut/Mb (Additional file 1: Figure $\mathrm{S} 1 \mathrm{~A}$ ), which was similar to the results of TCGA (mean TMB, 8.1 mut/Mb; median TMB, 8.4 mut/Mb), and CHOICE (mean TMB, 11.8 mut/Mb) study $[30,31]$. The common cutoffs for TMB include dichotomy, trichotomy, and quartering. In this study, we defined the high-TMB group as that with a TMB value at or above the median level and the low-TMB group as that with a TMB value below the median level. This definition for TMB cutoff is popular in the research setting because it is more helpful for us to clarify the relevant investigations due to its briefness. We observed that only ECOG PS $=0$ was associated with a significantly higher rate of samples with low TMB $(P=0.014)$. There was no significant relationship between TMB and other clinical features (Table 1). Of note, patients with CNVs had significantly higher TMB than those without CNVs $(P=0.008$; Additional file 1: Figure S1B). Two antibody assays (SP142 and E1L3N) were used to test PD-L1 expression. The representative IHC images were listed in Additional file 1: Figure S2A. A significant correlation of PD-L1 expression score between two assays was found $\left(R^{2}=0.782, P<0.001\right.$; Additional file 1: Figure S2B) while E1L3N had a higher mean score (Additional file 1: Figure S2C). Using cutoff of $5 \%(\mathrm{E} 1 \mathrm{~L} 3 \mathrm{~N}), \mathrm{PD}-\mathrm{L} 1^{+}$was observed in $24.3 \%$ of all cases (Additional file 1: Figure S4A), which was lower than it in Caucasian with LUSC [32]. Interestingly, in CHOICE study (includes both Chinese LUSC and LUAD), PD-L1 positivity rate was $23.1 \%$ using $H$ score $\geq 50$, or $63.9 \%$ using $>1 \%$ tumor cell positive as a cutoff, which is consistent with those in the literature on the Western population [31]. Only young age was associated with significantly higher rate of PD-L1 ${ }^{+}$ (31.43\% VS. $15.48 \%, P=0.011$; Table 1). No significant association was observed between PD-L1 expression and other clinical parameters. Patients with CNVs had similar PD-L1 expression score to those without CNVs $\left(P=0.816\right.$; Additional file 1: Figure S1C). $\mathrm{CD}^{+} \mathrm{TIL}^{+}$ was observed in $78.8 \%$ of all samples (Additional file 1 : Figure S4B) and representative IHC images of $\mathrm{CD}^{+}$ TIL were showed in Additional file 1: Figure S3. There was no significant correlation between $\mathrm{CD} 8^{+}$TIL density and clinicopathological features. Patients with CNVs had similar CD8 ${ }^{+}$TIL density to those without CNVs $(P=0.317$; Additional file 1: Figure S1D).

Although previous studies reported that there was no correlation between $\mathrm{TMB}$ and $\mathrm{PD}-\mathrm{L} 1$ expression in NSCLC [14, 32], we explored these relationships not only between TMB and PD-L1 expression but also between TMB and $\mathrm{CD}^{+}$TIL density. Consistently, no correlation 


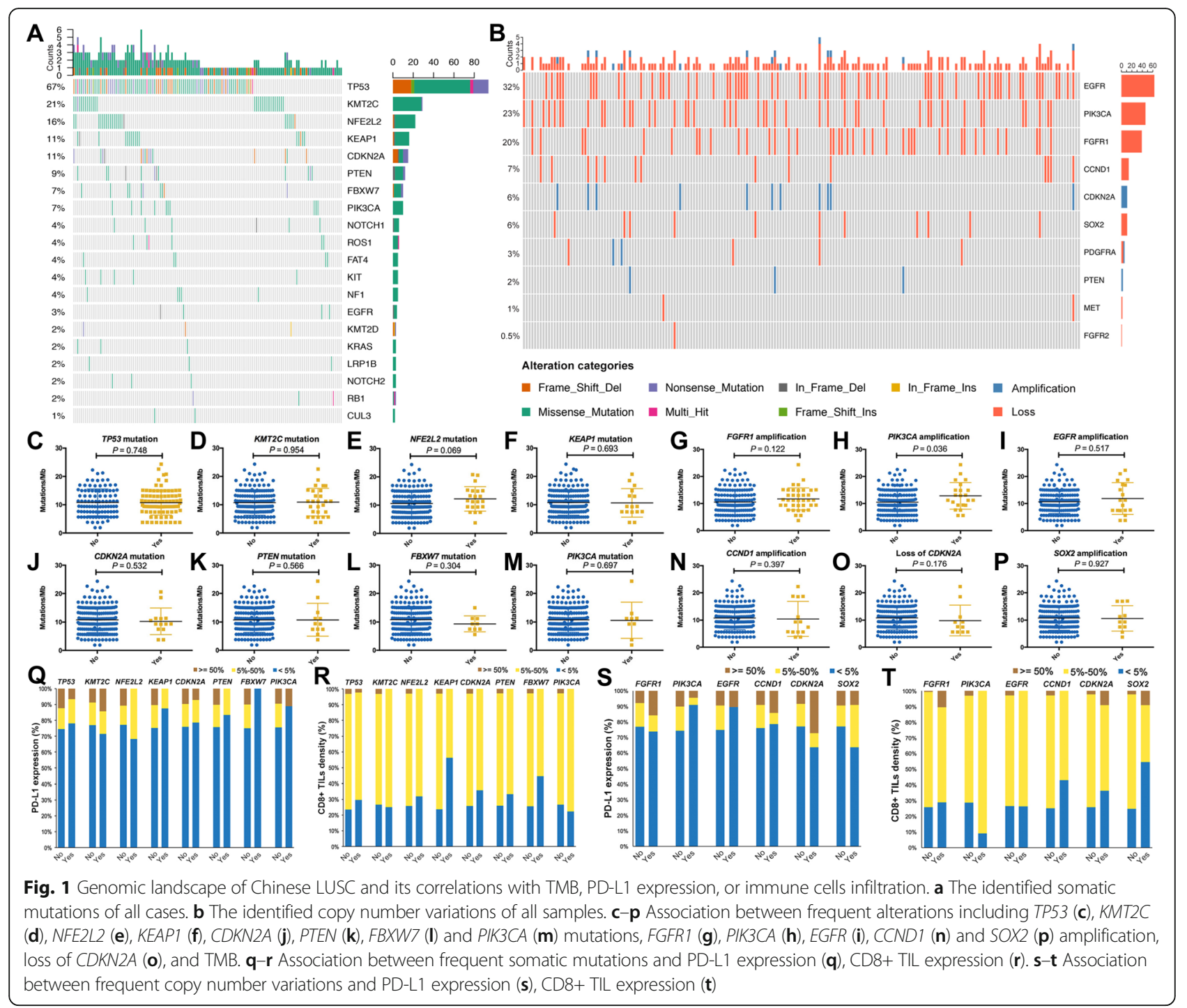

was found between TMB and PD-L1 expression (Spearman $R=0.052, P=0.475$; Additional file 1: Figure $\mathrm{S} 4 \mathrm{C})$, TMB and $\mathrm{CD}^{+}$TIL density (Spearman $R=0.026, P=0.724$; Additional file 1: Figure S4D). A significant positive correlation was found between PD-L1 expression and CD8 ${ }^{+}$TIL density (Spearman $R=0.232, P=0.001$; Additional file 1 : Figure S4E).

We then investigated the associations between frequent genomic alterations and TMB, PD-L1 expression, or $\mathrm{CD}^{+}$ TIL density. As shown in Fig. 1, PIK3CA amplification was associated with markedly higher TMB $(P=0.036$; Fig. 1e) and NFE2L2 mutation was associated with marginally higher TMB than those without $(P=0.069$; Fig. 1h). There was no significant association between other frequent somatic mutations and TMB (Fig. 1c-d, f-g, i-p) or PD-L1 expression (Fig. 1q, s). KEAP1 mutation was associated with dramatically lower $\mathrm{CD}^{+}$TIL density $(P=0.005$; Fig. 1 r $)$ while other frequent somatic mutations had no impact on CD8+ TIL density (Figure $1 \mathrm{R}$ and $1 \mathrm{~T}$ ). Using the online database, we further surveyed the impact of these frequent genomic alterations on six immune infiltrates. Consistent with our IHC results, we observed that only KEAP1 mutation had the negative impact on $\mathrm{CD}^{+} \mathrm{T}$ cell abundance $(P<0.05$; Additional file 1: Figure S5D). Both TP53 and $K E A P 1$ mutations were independently associated with significantly lower DCs and neutrophil infiltrations $(P<0.05$, $P<0.05$, respectively; Additional file 1 : Figures S5A and S5D). PIK3CA mutation was associated with significantly lower macrophage infiltration $(P<0.05$; Additional file 1 : Figure S5F) whereas other somatic mutations had no impact on the six immune infiltrates (Additional file 1: Figure S5). SOX2 amplification was associated with significantly lower $\mathrm{CD}^{+} \mathrm{T}$ cell abundance $(P<0.01$; Additional file 1: Figure S6F). Additionally, most of frequent CNVs 
including FGFR1, EGFR, and PIK3CA amplifications and loss of $C D K N 2 A$ were associated with significantly lower six immune infiltrates (Additional file 1: Figure S6).

\section{Impact of TMB, PD-L1 expression, and CD8 ${ }^{+}$TIL density on DFS and OS}

As shown in Fig. 2, high $\mathrm{CD}^{+}$TIL density and lower TMB were independently associated with significantly longer DFS $(P=0.010, P=0.040$, respectively). However, patients with different PD-L1 expression, CD8 ${ }^{+}$TIL density, and TMB had comparable OS $(P=0.176, P=0.493, P=0.310$, respectively; Fig. $2 g-i)$. Interestingly, a higher TMB cutoff was associated with a reduced statistical $P$ value of both
DFS and OS (Additional file 1: Figures S7 and S8). Although we chose $50 \%$ as the cutoff of PD-L1 ${ }^{+}$and $\mathrm{CD}^{+}$ $\mathrm{TIL}^{+}$, there was no significant difference of DFS and OS (Additional file 1: Figures S7 and S8). The combination of TMB and PD-L1 or CD8 ${ }^{+}$TIL could discriminate the populations with different DFS (Fig. 2d, e) but numerically distinct OS (Fig. 2). When we combined TMB with PD-L1 and $\mathrm{CD}^{+} \mathrm{TIL}$, the discriminatory power was significantly improved (Fig. 2f-l). Similarly, the discriminatory power was also improved along with the increase cutoffs of TMB (details in Additional file 1: Figures S7 and S8). Notably, the combination of TMB and $\mathrm{CD}^{+}$TIL density had a better discriminatory power than the combination of TMB

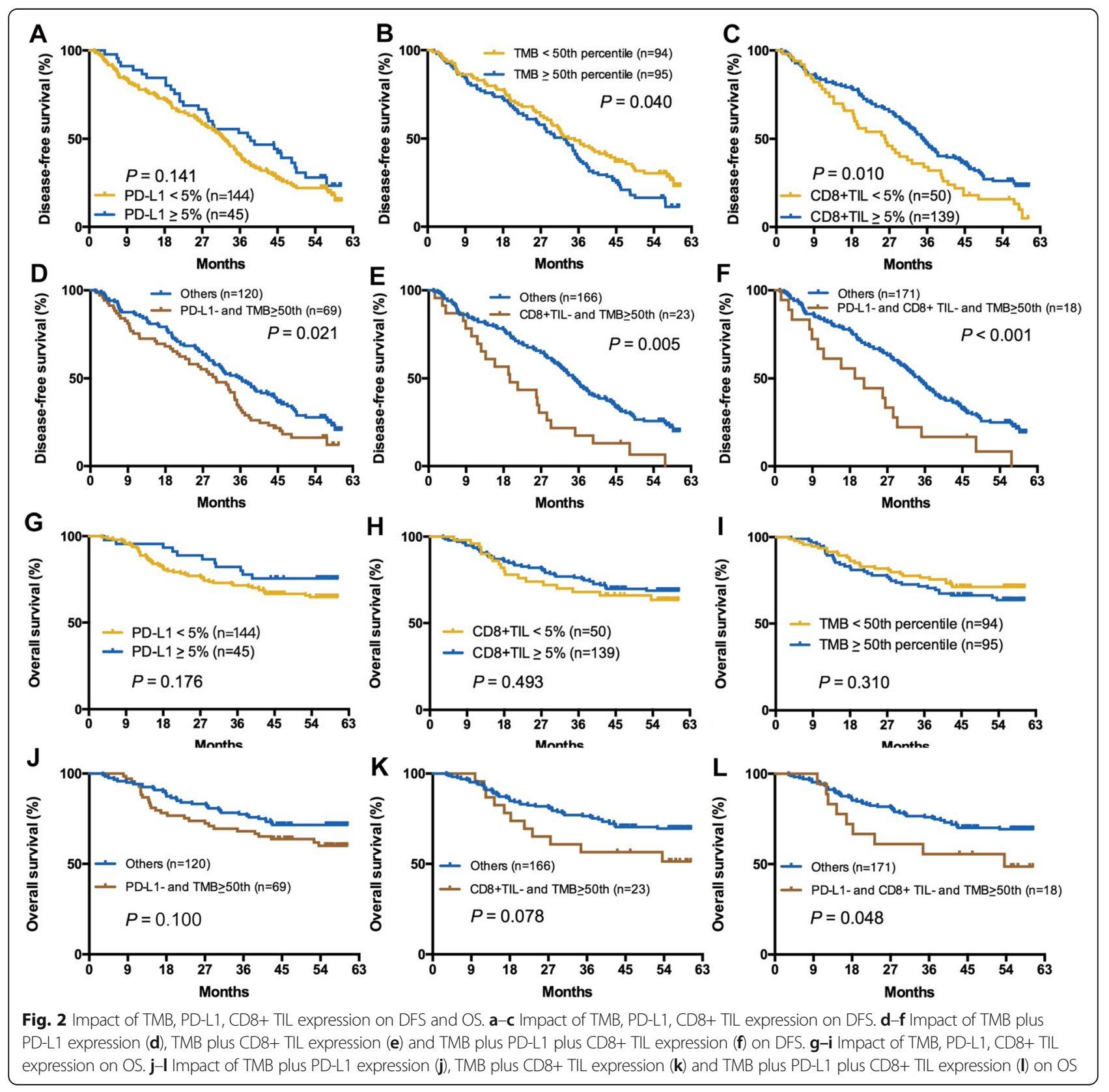


and PD-L1 expression in stratifying patients with discrepant DFS and OS.

Univariate analysis indicated that stages II and III were significantly associated with shorter DFS $(\mathrm{HR}=1.425$, $P=0.033)$ and $\mathrm{OS}(\mathrm{HR}=2.952, P<0.001)$ (Table 2). $\mathrm{CD}^{+} \mathrm{TIL}^{-}$, high TMB, PD-L1 ${ }^{-}$plus high TMB, and $\mathrm{CD}^{+} \mathrm{TIL}^{-}$plus high TMB were independently associated with shorter DFS $(P=0.010, P=0.040, P=0.021$, $P=0.005$, respectively) while $\mathrm{CD}^{+} \mathrm{TIL}^{+}$plus lower TMB was associated with longer DFS $(P=0.011)$. The combination of high TMB and PD-L1 ${ }^{-}$or $\mathrm{CD}^{+} \mathrm{TIL}^{-}$ did not reach the statistical significance in stratifying patients with different $\mathrm{OS}(P=0.100, P=0.078$, respectively). Multivariate analysis revealed that stages II and III were associated with both markedly poor DFS $(\mathrm{HR}=1.614$, $P=0.005)$ and $\mathrm{OS}(\mathrm{HR}=2.844, P<0.001)$. Only the combination of $\mathrm{CD}^{+} \mathrm{TIL}^{+}$and lower TMB was associated with significantly longer DFS $(\mathrm{HR}=0.506, P=0.043)($ Table 2$)$.

\section{Classification of tumor immune microenvironment based on PD-L1 expression and CD8 ${ }^{+}$TIL density}

According to previous classification method [33], we categorized the classification of tumor immune microenvironment (TIME) into four types based on PD-L1 expression and $\mathrm{CD} 8^{+}$TIL density (type I, PD- $\mathrm{L}^{+} \mathrm{CD}^{+} \mathrm{TIL}^{+}$; type II, PD-L1 ${ }^{-} \mathrm{CD}^{+} \mathrm{TIL}^{-}$; type III, PD-L1 ${ }^{+} \mathrm{CD}^{+} \mathrm{TIL}^{-}$; type IV, PD-L1 $\left.{ }^{-} \mathrm{CD}^{+} \mathrm{TIL}^{+}\right)$. We found that type IV $(n=111$, 58.7\%) TIME was dominant while type III $(n=8,4.2 \%)$ was the least common in Chinese early-stage LUSC (Fig. 3a). The percentage of types I and II were 19.6\% $(n=37)$ and $17.5 \%(n=33)$, respectively (Fig. 3a). This classification had no prognostic value $(P=0.488$; Fig. 3b). No significant correlation was found between types of TIME and age, sex, and smoking history (Fig. 3c-e). TMB was also comparable in different types of TIME $(P>0.05$; Fig. 3f). Notably, we observed that types II and IV TIME had a significantly higher frequency of genetic alterations than types I and III (Fig. 3g).

\section{Subgroup analysis according to smoking status}

Considering the impact of smoking history on TMB and TIME, and a high rate of never-smoker (31.7\%) in this cohort, we further conducted the subgroup analysis of the associations between TMB, PD-L1 expression, CD8 ${ }^{+}$ TIL density, and clinical features and outcomes according to the smoking status. As shown in Additional file 1: Table S2, the correlation between young age and PD-L1 ${ }^{+}$ was only found in never-smoker $(P=0.048)$. There was no any correlation between TMB, PD-L1 expression, or $\mathrm{CD} 8^{+}$TIL density and other clinical parameters in both groups. In never-smoking group, $\mathrm{PD}-\mathrm{L}^{+}{ }^{+}$was associated with marginally significantly longer DFS $(P=0.092$; Fig. 4a) but similar OS $\left(P=0.103\right.$; Fig. 4 d). $\mathrm{CD}^{+} \mathrm{TIL}^{+}$ was not associated with both DFS and OS (Fig. 4b, e). High TMB was correlated with significantly longer DFS $(P=0.021$; Fig. $4 \mathrm{c})$ but not $\mathrm{OS}(P=0.378$; Fig. $4 \mathrm{f})$. Intriguingly, in those with former/current smoking, both PD-L1 expression and TMB level were not correlated with DFS and OS (Fig. 4g, i, j, and l) while $\mathrm{CD}^{+} \mathrm{TIL}^{+}$ was associated with markedly longer DFS $(P=0.009$; Fig. 4h).

\section{Discussion}

Whole-exome sequencing of our cohort identified significant somatic mutations and $\mathrm{CNVs}$ that was consistent with previous publications on the genomic profile of early-stage LUSC [30, 31, 34, 35]. However, SOX2 amplification was only found in $6.0 \%$ of all cases, which was significantly lower than other studies [30, 34]. Importantly, we identified a high frequency of EML4-ALK fusion (3.2\%), one of the most common driver alterations in LUAD, which might mainly due to a high rate of neversmoker in our cohort, and infer the necessity to detect the common driver gene alterations in never-smokers with LUSC.

LUSC was previously found to have higher TMB than other solid tumors due to the close correlation to tobacco exposure [31, 36, 37]. However, the present study did not observe the association between smoking history and TMB level. In line with our results, Tatsuro et al. also did not find a correlation between the amount of smoking and TMB [35]. Furthermore, although the current cohort involved a large proportion of patients with never smoking, the mean and median TMB was similar to the results of TCGA and CHOICE study [30, 31]. These findings suggested that the relationship between tobacco exposure and TMB still remains further investigation. Intriguingly, patients with CNVs had significantly higher TMB than those without. This were reminiscent of an elegant study that examined the data from 5255 tumor/normal samples representing 12 tumor types from TCGA and found a positive correlation between somatic CNVs level and the total number of mutations [38], suggesting the potential value of CNVs for predicting the TMB level and its application for predicting who are most likely to benefit from immunotherapy. Of note, some kinds of CNVs, such as FGFR1, EGFR, and PIK3CA amplifications and loss of $C D K N 2 A$, were associated with significantly lower six immune infiltrates. This finding could partly explain that the fraction of copy number altered genome was highest in NSCLC patients treated with anti-PD-1/PD-L1 therapy but lack of durable benefit due to the importance of these immune infiltrates in antitumor immune response [14]. It also indicated that distinct kinds of CNVs would have a different effect on the immune response.

Understanding the interplay between molecular underpinnings and immune landscape may help improve 
Table 2 Univariate and multivariate analyses of clinical parameters on disease-free survival and overall survival

\begin{tabular}{|c|c|c|c|c|c|c|}
\hline \multirow[t]{2}{*}{ Factor } & \multicolumn{3}{|c|}{ Univariate analysis } & \multicolumn{3}{|c|}{ Multivariate analysis } \\
\hline & HR (log rank) & $95 \% \mathrm{Cl}$ & $P$ value & HR (log rank) & $95 \% \mathrm{Cl}$ & $P$ value \\
\hline \multicolumn{7}{|l|}{ Disease-free survival } \\
\hline Sex (female/male) & 0.818 & $0.416-1.606$ & 0.559 & & & \\
\hline Age $(\geq 65 /<65)$ & 1.030 & $0.742-1.429$ & 0.862 & & & \\
\hline Smoking (yes/no) & 0.892 & $0.632-1.257$ & 0.513 & & & \\
\hline$P S(\geq 1 / 0)$ & 1.092 & $0.759-1.571$ & 0.636 & & & \\
\hline Stage $(||-|||/|)$ & 1.425 & $1.028-1.973$ & 0.033 & 1.614 & $1.156-2.255$ & 0.005 \\
\hline Pleural invasion (yes/no) & 1.629 & $0.900-2.950$ & 0.107 & & & \\
\hline Vascular invasion (yes/no) & 1.674 & $0.819-3.420$ & 0.158 & & & \\
\hline Differentiation (high/non-high) & 1.080 & $0.505-2.309$ & 0.842 & & & \\
\hline PD-L1 (positive/negative) & 0.702 & $0.474-1.041$ & 0.141 & & & \\
\hline CD8 ${ }^{+}$TIL (positive/negative) & 0.632 & $0.444-0.898$ & 0.010 & 0.711 & $0.429-1.180$ & 0.187 \\
\hline 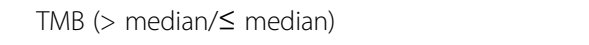 & 1.454 & $1.047-2.019$ & 0.040 & 1.122 & $0.652-1.929$ & 0.677 \\
\hline PD-L1 negative and TMB > median VS. others & 1.533 & $1.097-2.140$ & 0.021 & 1.176 & $0.708-1.954$ & 0.530 \\
\hline PD-L1 negative and TMB $\leq$ median VS. others & 0.884 & $0.633-1.235$ & 0.470 & & & \\
\hline PD-L1 positive and TMB $\leq$ median VS. others & 0.506 & $0.272-0.938$ & 0.031 & 0.506 & $0.261-0.979$ & 0.043 \\
\hline PD-L1 positive and TMB > median VS. others & 0.972 & $0.611-1.544$ & 0.903 & & & \\
\hline CD8 ${ }^{+}$TIL negative and TMB $>$median VS. others & 2.224 & $1.405-3.520$ & 0.005 & 1.416 & $0.695-2.888$ & 0.338 \\
\hline $\mathrm{CD} 8^{+} \mathrm{TIL}$ negative and $\mathrm{TMB} \leq$ median VS. others & 1.102 & $0.705-1.720$ & 0.670 & & & \\
\hline $\mathrm{CD}^{+} \mathrm{TIL}$ positive and $\mathrm{TMB} \leq$ median VS. others ${ }^{\#}$ & 0.629 & $0.441-0.898$ & 0.011 & & & \\
\hline CD8 ${ }^{+}$TIL positive and TMB $>$median VS. others & 1.070 & $0.767-1.495$ & 0.689 & & & \\
\hline \multicolumn{7}{|l|}{ Overall survival } \\
\hline Sex (female/male) & 1.012 & $0.317-3.229$ & 0.984 & & & \\
\hline Age $(\geq 65 /<65)$ & 1.252 & $0.758-2.068$ & 0.381 & & & \\
\hline Smoking (yes/no) & 1.038 & $0.604-1.785$ & 0.892 & & & \\
\hline$P S(\leq 1 / 0)$ & 0.995 & $0.562-1.761$ & 0.987 & & & \\
\hline Stage $(||-|||/|)$ & 2.952 & $1.685-5.172$ & $<0.001$ & 2.844 & $1.606-5.038$ & $<0.001$ \\
\hline Pleural invasion (yes/no) & 1.425 & $0.613-3.309$ & 0.411 & & & \\
\hline Vascular invasion (yes/no) & 2.214 & $0.886-5.534$ & 0.089 & 1.660 & $0.646-4.268$ & 0.293 \\
\hline Differentiation (high/non-high) & 1.892 & $0.758-4.727$ & 0.172 & & & \\
\hline PD-L1 (positive/negative) & 0.701 & $0.373-1.318$ & 0.270 & & & \\
\hline CD8 ${ }^{+}$TIL (positive/negative) & 0.825 & $0.476-1.430$ & 0.493 & & & \\
\hline 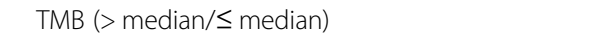 & 1.366 & $0.824-2.263$ & 0.227 & & & \\
\hline PD-L1 negative and TMB $>$ median VS. others & 1.591 & $0.960-2.638$ & 0.100 & 1.425 & $0.822-2.468$ & 0.207 \\
\hline PD-L1 negative and TMB $\leq$ median VS. others & 0.818 & $0.485-1.380$ & 0.452 & & & \\
\hline PD-L1 positive and TMB $\leq$ median VS. others & 0.707 & $0.283-1.765$ & 0.457 & & & \\
\hline PD-L1 positive and TMB > median VS. others & 0.753 & $0.343-1.656$ & 0.481 & & & \\
\hline $\mathrm{CD} 8^{+} \mathrm{TIL}$ negative and $\mathrm{TMB}>$ median VS. others & 1.785 & $0.929-3.341$ & 0.078 & 1.652 & $0.811-3.364$ & 0.166 \\
\hline $\mathrm{CD}^{+} \mathrm{TIL}$ negative and $\mathrm{TMB} \leq$ median VS. others & 0.753 & $0.343-1.654$ & 0.480 & & & \\
\hline 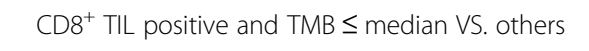 & 0.819 & $0.480-1.398$ & 0.464 & & & \\
\hline 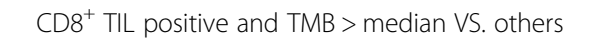 & 1.031 & $0.614-1.730$ & 0.909 & & & \\
\hline
\end{tabular}




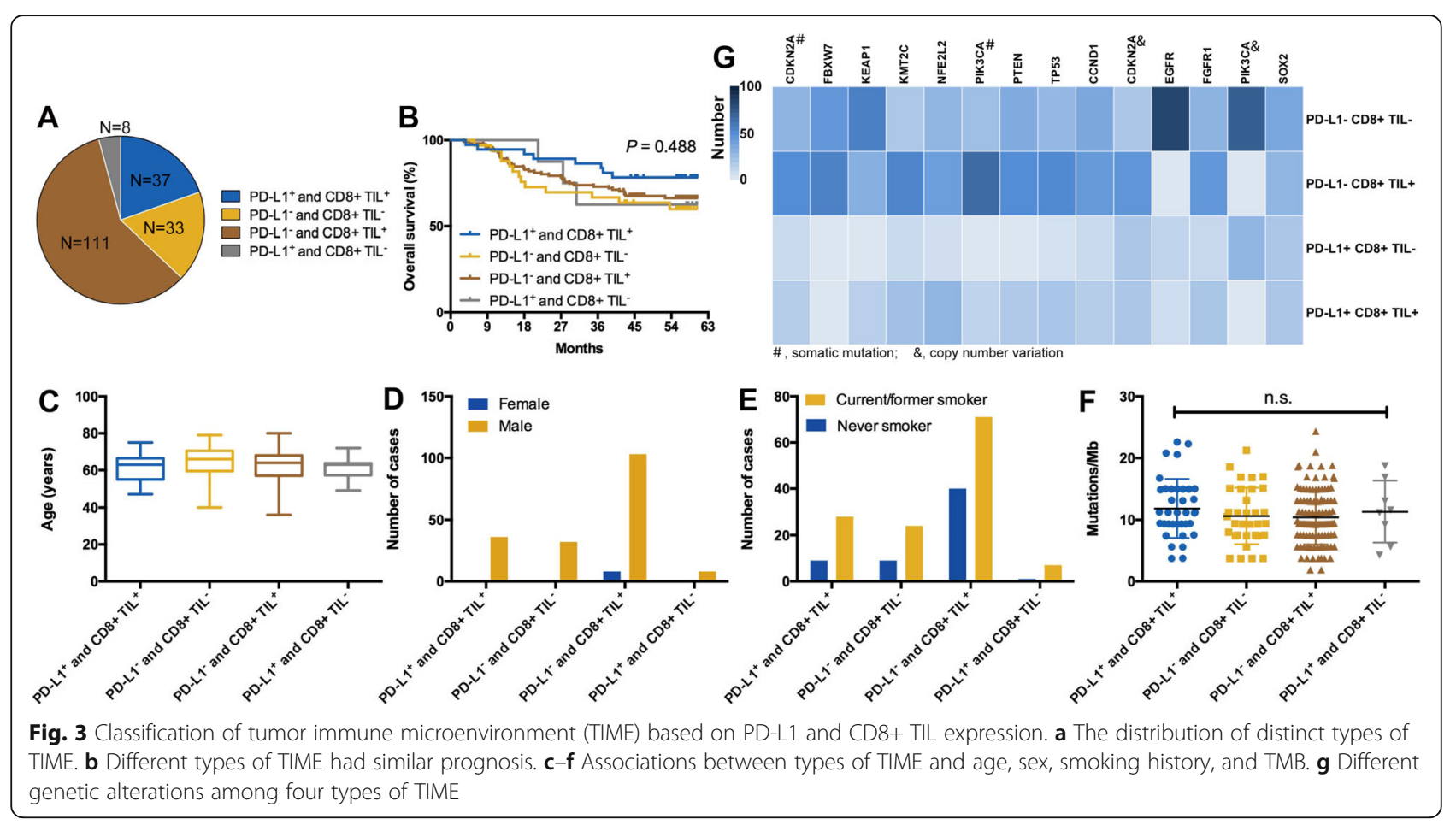

strategies for precise immunotherapy [14, 39]. Towards this aim, we investigated the associations between frequent genomic alterations and PD-L1 expression, TMB, or $\mathrm{CD}^{+}$TIL density. The results showed that only KEAP1 mutation was significantly associated with lower $\mathrm{CD}^{+}$TIL density, and NFE2L2 mutation was associated with marginally higher TMB. Moreover, a recent study reported that there was a higher rate of KEAP1/NFE2L2 $>$ mutations in Chinese LUSC than those in Western populations [31]. KEAP1-NFE2L2 interaction plays a significant role in the dysregulation of oxidative stress pathway in lung cancer [40]. Genetic alterations of KEAP1 or NFE2L2 would destroy this process and lead to oncogenesis and drug and radio resistance in different types of solid tumors. Considering these findings, we could infer that tumor with KEAP1 or NFE2L2 mutation would have a higher level of oxidative stress, which could lead to the destruction of immune cells including $\mathrm{CD} 8^{+}$TILs and increased DNA damage level, resulting in the increase of somatic mutations of tumor cells. We also used the online database to calculate the abundance of tumor-infiltrating immune cells [28, 29]. Consistent with our IHC results, we observed that KEAP1 mutation had the negative effect on $\mathrm{CD}^{+} \mathrm{T}$ cell abundance. KEAP1 mutation was reported to be associated with poor response to adjuvant chemotherapy in both LUSC and LUAD [19, 34, 41]. Whether the relationship between KEAP1 mutation and lower $\mathrm{CD}^{+} \mathrm{T}$ cell infiltration could explain the negative predictive value on adjuvant chemotherapy warrants further examinations.
Currently, TMB and PD-L1 expression are the two developed predictive biomarkers for anti-PD-1/PD-L1 therapy. We found no association between TMB and PD-L1 expression, which was consistent with previous findings. Yu et al. reported that PD-L1 protein expression was not correlated with TMB in both tumor cells and tumor-infiltrating immune cells of early-stage LUSC [32]. Rizvi et al. also found that TMB did not correlate with PD-L1 expression in patients with NSCLC treated with anti-PD-1/PD-L1 therapy [14]. Moreover, our study indicated that TMB did not correlate with $\mathrm{CD}^{+} \mathrm{TIL}$ density but a significant positive correlation was found between $\mathrm{CD} 8^{+}$TIL density and PD-L1 expression. Similar to previous reports $[42,43]$, positive $\mathrm{CD}^{+}$TIL density and lower TMB were independently associated with significantly longer DFS even though none of TMB, PDL1 expression, or $\mathrm{CD}^{+}$TIL density were associated with OS. The combination of TMB and PD-L1 expression or $\mathrm{CD} 8^{+}$TIL density showed an improved yield in stratifying patients with discrepant DFS and OS, suggesting that the incorporation of these biomarkers into multivariable predictive and prognostic models worth further investigation in the future.

Furthermore, we classified the TIME into four types based on PD-L1 expression and CD8 ${ }^{+}$TIL density. Our data indicated that type IV TIME was dominant while type III was the least common in Chinese early-stage LUSC, which is in contrast to the previous studies [21, 44]. The potential reasons may include the different populations, testing methods and platforms, together with the 


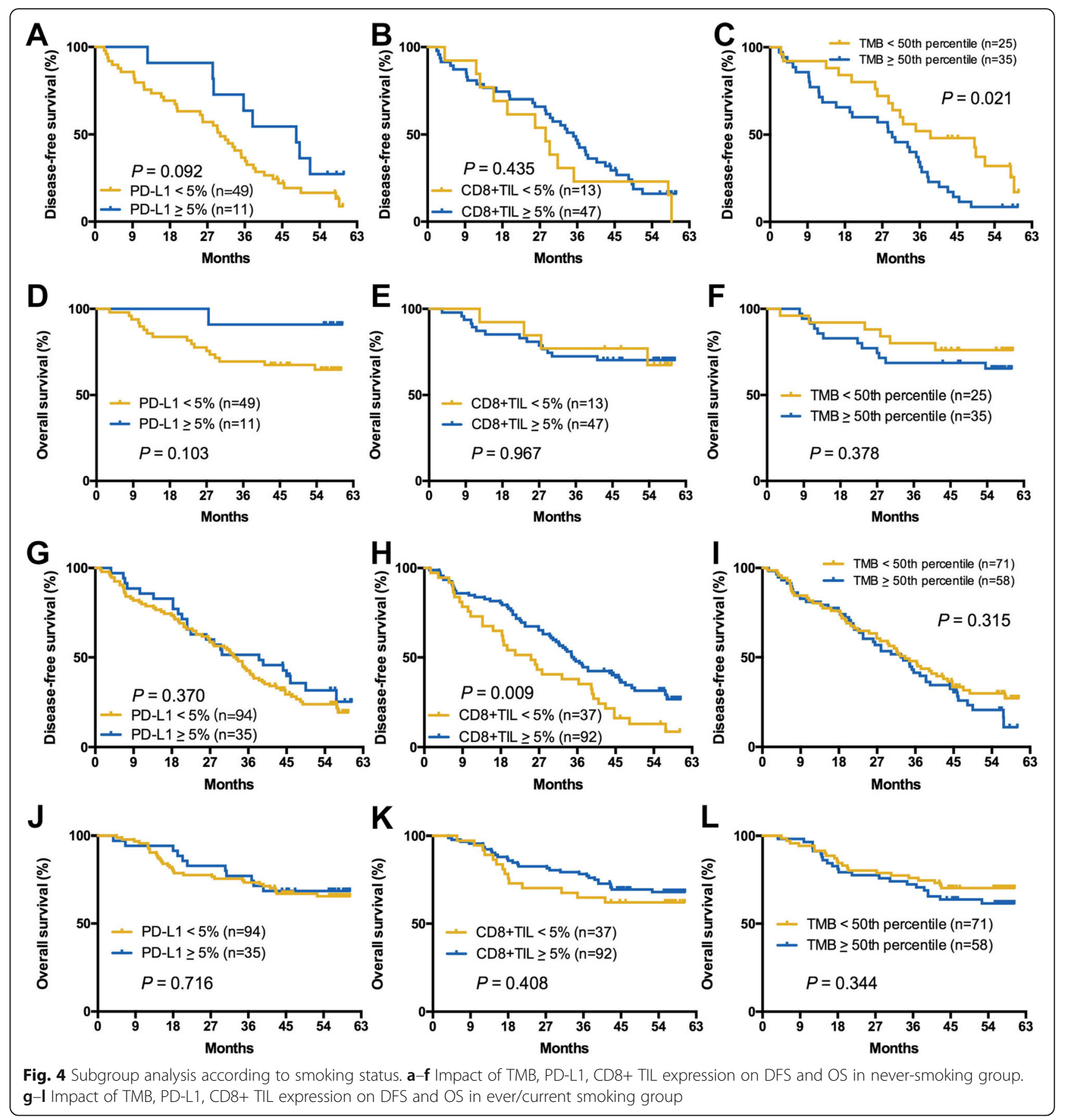

discrepancy between the online RNA-seq and IHC staining data. As we know, type I TIME is most likely to benefit from anti-PD-1/PD-L1 monotherapy for the reason that these tumors have evidence of pre-existing intratumor $\mathrm{T}$ cells that are silenced by PD-L1 engagement. Constantly, the proportion of type I TIME in our cohort was similar to the response rate of patients with LUSC received singleagent anti-PD-1/PD-L1 checkpoint blockade [7-9]. We also found that different types of TIME had distinct genetic alterations but similar TMB, clinical variables, and prognosis, suggesting the unique shaping function of genomic landscape on immune phenotypes.

Additionally, we observed that high TMB was correlated with significantly longer DFS in never-smoker but not associated with DFS in former/current smoker. $\mathrm{CD}^{+} \mathrm{TIL}^{+}$ was not associated with DFS in never-smoker but associated with markedly longer DFS in former/current smoker. Both TMB level and CD8 ${ }^{+}$TIL+ were not associated with OS. PD-L1 ${ }^{+}$was not correlated with both DFS and OS in two groups. NSCLC of never-smokers are entirely different 
from these of former/current smokers. In never-smoking group, high TMB in tumors with never-smoking would mainly come from the intrinsic mechanism, which means the high possibility to be recognized and eliminated by the immune system. In this process, more and more $\mathrm{CD}^{+}$ TILs would be induced and translated into the exhausted phenotype. Hence, high TMB was correlated with significantly longer DFS but CD8 ${ }^{+} \mathrm{TIL}+$ was not associated with DFS in never-smoker. Conversely, high TMB in smokers caused by tobacco exposure could not predict the clinical outcome. However, CD $8^{+}$TILs in smokers could recognize and eliminate the malignant cells after exposure to the different carcinogens. Hence, high $\mathrm{CD}^{+}$TIL density was found to associate with markedly longer DFS in the current study. We must mention that the relatively small sample size and multiple different subsets based on distinct cutoffs of TMB, PD-L1 expression, CD8 ${ }^{+}$TIL density, and/or smoking status for these exploratory analyses would also be the potential reason for these discrepancies. Future investigations with a larger number of patients with LUSC are still needed.

\section{Conclusions}

In summary, this large-scale study found PIK3CA amplification was associated with higher TMB but lower $\mathrm{CD}^{+} \mathrm{T}$ cells density while the common genetic alterations had no impact on PD-L1 expression. Combination of TMB and PD-L1/CD8 + TIL could be helpful to stratify the whole population into distinct DFS and OS subgroups. TIME classifications according to PD-L1 expression and $\mathrm{CD} 8^{+}$ TIL density showed distinct genomic alterations but similar TMB, clinical variables, and prognosis. Notably, TMB and $\mathrm{CD}^{+}$TIL+ might have a distinct role in patients with different smoking status. These findings shed a light and might be helpful to guide future design of personalized immunotherapy trials in LUSC.

\section{Additional file}

Additional file 1: Figure S1. (A) the distribution of TMB; (B-D) the comparison of TMB (B), PD-L1 expression (C), and CD8 $8^{+}$TIL density (D) between patients with CNVs and those without CNVs. Figure S2. (A) The representative immunohistochemical images of PD- $L 1$ expression, (B) the correlations of PD-L1 expression score between SP142 and E1L3N, and (C) the distribution of PD-L1 expression score in each antibody assay. Figure S3. The representative immunohistochemical images of CD8+ TIL expression. Figure S4. The distribution of different PD-L1 expression (A) and CD8 ${ }^{+}$TIL density (B); (C) correlation between TMB and PD-L1 expression, (F) TMB and CD8 ${ }^{+}$TIL density, and (E) PD-L1 expression and CD8 ${ }^{+}$ TIL density. Figure S5. Association between frequent somatic mutations and six immune cells infiltration. Figure S6. Association between frequent CNVs and six immune cells infiltration. Figure S7. DFS at PD-L1 expression cutoff of 5\% (A) and 50\% (B); CD8 ${ }^{+}$TIL expression cutoff of 5\% (C) and 50\% (D); TMB cutoff of 25th (E), 50th (F), 75th (G) and 90th (H) percentile; TMB plus PD-L1 at TMB cutoff of 25th (I), 50th (J), 75th (K) and 90th $(\mathrm{L})$ percentile; TMB plus CD8 $8^{+}$TIL expression at TMB cutoff of 25 th $(\mathrm{M})$, 50th $(\mathrm{N})$, 75th $(\mathrm{O})$ and 90th $(\mathrm{P})$ percentile. Figure S8. OS at PD-L1 cutoff of $5 \%(A)$ and $50 \%(B) ; C D 8^{+}$TIL expression cutoff of $5 \%(C)$ and
$50 \%(\mathrm{D})$; TMB cutoff of 25th (E), 50th (F), 75th (G) and 90th (H) percentile; TMB plus PD-L1 at TMB cutoff of 25th (I), 50th (J), 75th (K) and 90th (L) percentile; TMB plus CD8 ${ }^{+}$TIL expression at TMB cutoff of 25th (M), 50th $(\mathrm{N})$, 75th $(\mathrm{O})$ and 90th $(\mathrm{P})$ percentile. Table $\mathbf{S 1}$. The relationship between EGFR amplification/EML4-ALK fusion and clinicopathological features. Table S2. Baseline characteristics of included patients according to smoking status. (DOCX $3849 \mathrm{~kb})$

\section{Abbreviations}

Cl: Confidence interval; CNV: Copy number variation; DC: Dendritic cell; DFS: Disease-free survival; ECOG PS: Eastern Cooperative Oncology Group performance status; FFPE: Formalin-fixed and paraffin-embedded; HR: Hazard ratios; IHC: Immunohistochemistry; LUAD: Lung adenocarcinoma; LUSC: Lung squamous cell carcinoma; NSCLC: Non-small-cell lung cancer; OS: Overall survival; PD-1: Programmed cell death 1; PD-L1: Programmed cell death ligand 1; SNV: Single nucleotide variant; TIL: Tumor-infiltrating lymphocytes; TIME: Tumor immune microenvironment; TMB: Tumor mutation burden; TPS: Tumor proportion score

\section{Publisher's Note}

Springer Nature remains neutral with regard to jurisdictional claims in published maps and institutional affiliations.

\section{Acknowledgements}

Not applicable.

\section{Authors' contributions}

All authors participated in the planning and execution of this study or analysis of the study data. TJ and CaZ designed this study. All authors collected the data and conducted the relevant experiments. TJ, JS, ChZ, XL, $B M, W Z, X G, H Z$, and JH performed the statistical analyses. ZD, LH, and $C W$ performed all the pathological evaluation. TJ, SR, and CaZ drafted the manuscript. CaZ, XC, CS, and SR provided critical comments and suggestions and revised the manuscript. All authors read and approved the final version of the manuscript. Beijing Genecast Biotechnology Co. conducted the whole-exome sequencing of all included samples.

\section{Funding}

This study was supported in part by grants from the National Natural Science Foundation of China (No. 81672286, 81772467, and 81874036), "Shuguang Program" supported by Shanghai Education Development Foundation and Shanghai Municipal Education Commission (No. 16SG18), the Chronic Diseases Program of Shanghai Shen Kang Pharmaceutical Development Co. Ltd (No. SHDC 12015314), Shanghai Municipal Science and Technology Commission Basic Research Innovation Plan (No. 16JC1405900), and Shanghai Municipal Science and Technology Commission Medical Guidance Project (No. 16411964400).

\section{Availability of data and materials}

Not applicable.

Ethics approval and consent to participate Not applicable.

\section{Consent for publication}

Not applicable.

\section{Competing interests}

Beibei Mao, Wei Zhu, Xianchao Guo, Henghui Zhang, and Ji He are employees of Beijing Genecast Biotechnology Co., Beijing, China. The other authors declare that they have no conflicts of interest.

\section{Author details}

'Department of Medical Oncology, Shanghai Pulmonary Hospital \& Thoracic Cancer Institute, Tongji University School of Medicine, Zheng Min Road, Shanghai 200433, China. ${ }^{2}$ Department of Pathology, Shanghai Pulmonary Hospital \& Thoracic Cancer Institute, Tongji University School of Medicine, Shanghai 200433, China. ${ }^{3}$ Department of Lung Cancer and Immunology, Shanghai Pulmonary Hospital, Tongji University School of Medicine, No. 507, 
Zheng Min Road, Shanghai 200433, China. ${ }^{4}$ Beijing Genecast Biotechnology Co., Beijing 100191, China.

\section{Received: 3 May 2019 Accepted: 25 June 2019}

Published online: 12 July 2019

\section{B.References}

1. Perez-Moreno P, Brambilla E, Thomas R, Soria JC. Squamous cell carcinoma of the lung: molecular subtypes and therapeutic opportunities. Clin Cancer Res. 2012;18:2443-51.

2. Chen Z, Fillmore CM, Hammerman PS, Kim CF, Wong KK. Non-small-cell lung cancers: a heterogeneous set of diseases. Nat Rev Cancer. 2014;14:53546.

3. Gandara DR, Hammerman PS, Sos ML, Lara PN Jr, Hirsch FR. Squamous cell lung cancer: from tumor genomics to cancer therapeutics. Clin Cancer Res. 2015;21:2236-43.

4. Reck M, Rabe KF. Precision diagnosis and treatment for advanced nonsmall-cell lung cancer. N Engl J Med. 2017;377:849-61.

5. Herbst RS, Morgensztern D, Boshoff C. The biology and management of non-small cell lung cancer. Nature. 2018;553:446-54.

6. Langer CJ, Obasaju C, Bunn P, Bonomi P, Gandara D, Hirsch FR, Kim ES, Natale RB, Novello S, Paz-Ares L, Perol M, Reck M, Ramalingam SS, Reynolds CH, Socinski MA, Spigel DR, Wakelee H, Mayo C, Thatcher N. Incremental innovation and progress in advanced squamous cell lung cancer: current status and future impact of treatment. J Thorac Oncol. 2016;11:2066-81.

7. Brahmer J, Reckamp KL, Baas P, Crino L, Eberhardt WE, Poddubskaya E, Antonia S, Pluzanski A, Vokes EE, Holgado E, Waterhouse D, Ready N, Gainor J, Aren Frontera O, Havel L, Steins M, Garassino MC, Aerts JG, Domine M, Paz-Ares L, Reck M, Baudelet C, Harbison CT, Lestini B, Spigel DR. Nivolumab versus docetaxel in advanced squamous-cell non-small-cell lung cancer. $\mathrm{N}$ Engl J Med. 2015;373:123-35.

8. Herbst RS, Baas P, Kim DW, Felip E, Perez-Gracia JL, Han JY, Molina J, Kim JH, Arvis CD, Ahn MJ, Majem M, Fidler MJ, de Castro G Jr, Garrido M, Lubiniecki GM, Shentu Y, Im E, Dolled-Filhart M, Garon EB. Pembrolizumab versus docetaxel for previously treated, PD-L1-positive, advanced non-small-cell lung cancer (KEYNOTE-010): a randomised controlled trial. Lancet. 2016;387: $1540-50$.

9. Rittmeyer A, Barlesi F, Waterkamp D, Park K, Ciardiello F, von Pawel J, Gadgeel SM, Hida T, Kowalski DM, Dols MC, Cortinovis DL, Leach J, Polikoff J, Barrios C, Kabbinavar F, Frontera OA, De Marinis F, Turna H, Lee JS, Ballinger M, Kowanetz M, He P, Chen DS, Sandler A, Gandara DR, Group OAKS. Atezolizumab versus docetaxel in patients with previously treated non-small-cell lung cancer (OAK): a phase 3, open-label, multicentre randomised controlled trial. Lancet. 2017;389:255-65.

10. Reck M, Rodriguez-Abreu D, Robinson AG, Hui R, Csoszi T, Fulop A, Gottfried M, Peled N, Tafreshi A, Cuffe S, O'Brien M, Rao S, Hotta K, Leiby MA, Lubiniecki GM, Shentu Y, Rangwala R, Brahmer JR, Investigators K. Pembrolizumab versus chemotherapy for PD-L1-positive non-small-cell lung cancer. N Engl J Med. 2016;375:1823-33.

11. Paz-Ares L, Luft A, Vicente D, Tafreshi A, Gumus M, Mazieres J, Hermes B, Cay Senler F, Csoszi T, Fulop A, Rodriguez-Cid J, Wilson J, Sugawara S, Kato T, Lee KH, Cheng Y, Novello S, Halmos B, Li X, Lubiniecki GM, Piperdi B, Kowalski DM, Investigators K-. Pembrolizumab plus chemotherapy for squamous non-small-cell lung cancer. N Engl J Med 2018; 379: 2040-2051.

12. Mok TSK, Wu YL, Kudaba I, Kowalski DM, Cho BC, Turna HZ, Castro G, Jr., Srimuninnimit V, Laktionov KK, Bondarenko I, Kubota K, Lubiniecki GM, Zhang J, Kush D, Lopes G, Investigators K-. Pembrolizumab versus chemotherapy for previously untreated, PD-L1-expressing, locally advanced or metastatic non-small-cell lung cancer (KEYNOTE-042): a randomised, open-label, controlled, phase 3 trial. Lancet 2019; 393: 1819-1830.

13. Hellmann MD, Ciuleanu TE, Pluzanski A, Lee JS, Otterson GA, AudigierValette C, Minenza E, Linardou H, Burgers S, Salman P, Borghaei H, Ramalingam SS, Brahmer J, Reck M, O'Byrne K, Geese WJ, Green G, Chang H, Szustakowski J, Bhagavatheeswaran P, Healey D, Fu Y, Nathan F, Paz-Ares L. Nivolumab plus ipilimumab in lung cancer with a high tumor mutational burden. N Engl J Med. 2018;378:2093-104.

14. Rizvi H, Sanchez-Vega F, La K, Chatila W, Jonsson P, Halpenny D, Plodkowski A, Long N, Sauter JL, Rekhtman N, Hollmann T, Schalper KA, Gainor JF, Shen R, Ni A, Arbour KC, Merghoub T, Wolchok J, Snyder A, Chaft JE, Kris MG, Rudin CM, Socci ND, Berger MF, Taylor BS, Zehir A, Solit DB, Arcila ME, Ladanyi M, Riely GJ, Schultz N, Hellmann MD.
Molecular determinants of response to anti-programmed cell death (PD)-1 and anti-programmed death-ligand 1 (PD-L1) blockade in patients with non-small-cell lung cancer profiled with targeted nextgeneration sequencing. J Clin Oncol. 2018;36:633-41.

15. Galluzzi L, Chan TA, Kroemer G, Wolchok JD, Lopez-Soto A. The hallmarks of successful anticancer immunotherapy. Sci Transl Med. 2018;10.

16. Cristescu R, Mogg R, Ayers M, Albright A, Murphy E, Yearley J, Sher X, Liu XQ, Lu H, Nebozhyn M, Zhang C, Lunceford JK, Joe A, Cheng J, Webber AL, Ibrahim N, Plimack ER, Ott PA, Seiwert TY, Ribas A, McClanahan TK, Tomassini JE, Loboda A, Kaufman D. Pan-tumor genomic biomarkers for PD1 checkpoint blockade-based immunotherapy. Science. 2018;362.

17. Arriagada R, Dunant A, Pignon JP, Bergman B, Chabowski M, Grunenwald D, Kozlowski M, Le Pechoux C, Pirker R, Pinel MI, Tarayre M, Le Chevalier T. Long-term results of the international adjuvant lung cancer trial evaluating adjuvant Cisplatin-based chemotherapy in resected lung cancer. J Clin Oncol. 2010;28:35-42.

18. Forde PM, Chaft JE, Smith KN, Anagnostou V, Cottrell TR, Hellmann MD, Zahurak M, Yang SC, Jones DR, Broderick S, Battafarano RJ, Velez MJ, Rekhtman N, Olah Z, Naidoo J, Marrone KA, Verde F, Guo H, Zhang J, Caushi JX, Chan HY, Sidhom JW, Scharpf RB, White J, Gabrielson E, Wang H, Rosner GL, Rusch V, Wolchok JD, Merghoub T, Taube JM, Velculescu VE, Topalian SL, Brahmer JR, Pardoll DM. Neoadjuvant PD-1 blockade in resectable lung cancer. N Engl J Med. 2018;378:1976-86.

19. Kadara H, Choi M, Zhang J, Parra ER, Rodriguez-Canales J, Gaffney SG, Zhao Z, Behrens C, Fujimoto J, Chow C, Yoo Y, Kalhor N, Moran C, Rimm D, Swisher S, Gibbons DL, Heymach J, Kaftan E, Townsend JP, Lynch TJ, Schlessinger J, Lee J, Lifton RP, Wistuba II, Herbst RS. Whole-exome sequencing and immune profiling of early-stage lung adenocarcinoma with fully annotated clinical follow-up. Ann Oncol. 2017;28:75-82.

20. Chalela R, Curull V, Enriquez C, Pijuan L, Bellosillo B, Gea J. Lung adenocarcinoma: from molecular basis to genome-guided therapy and immunotherapy. J Thorac Dis. 2017:9:2142-58.

21. Ock CY, Keam B, Kim S, Lee JS, Kim M, Kim TM, Jeon YK, Kim DW, Chung DH, Heo DS. Pan-cancer immunogenomic perspective on the tumor microenvironment based on PD-L1 and CD8 T-cell infiltration. Clin Cancer Res. 2016;22:2261-70.

22. Rimm DL, Han G, Taube JM, Yi ES, Bridge JA, Flieder DB, Homer R, West WW, Wu H, Roden AC, Fujimoto J, Yu H, Anders R, Kowalewski A, Rivard C, Rehman J, Batenchuk C, Burns V, Hirsch FR, Wistuba II. A prospective, multiinstitutional, pathologist-based assessment of 4 immunohistochemistry assays for PD-L1 expression in non-small cell lung cancer. JAMA Oncol. 2017;3:1051-8.

23. Yang $H$, Shi J, Lin D, Li X, Zhao C, Wang $Q$, Zhang L, Jiang T, Zhao S, Liu X, Jia Y, Zhang Y, Cai W, Zhou C. Prognostic value of PD-L1 expression in combination with CD8(+) TILs density in patients with surgically resected non-small cell lung cancer. Cancer Med. 2018;7:32-45.

24. Takada K, Okamoto T, Toyokawa G, Kozuma Y, Matsubara T, Haratake N, Akamine T, Takamori S, Katsura M, Shoji F, Oda Y, Maehara Y. The expression of PD-L1 protein as a prognostic factor in lung squamous cell carcinoma. Lung Cancer. 2017;104:7-15.

25. Hirsch FR, McElhinny A, Stanforth D, Ranger-Moore J, Jansson M, Kulangara K, Richardson W, Towne P, Hanks D, Vennapusa B, Mistry A, Kalamegham R, Averbuch S, Novotny J, Rubin E, Emancipator K, McCaffery I, Williams JA, Walker J, Longshore J, Tsao MS, Kerr KM. PD-L1 immunohistochemistry assays for lung cancer: results from phase 1 of the blueprint PD-L1 IHC assay comparison project. J Thorac Oncol. 2017;12:208-22.

26. Herbst RS, Soria JC, Kowanetz M, Fine GD, Hamid O, Gordon MS, Sosman JA, McDermott DF, Powderly JD, Gettinger SN, Kohrt HE, Horn L, Lawrence DP, Rost S, Leabman M, Xiao Y, Mokatrin A, Koeppen H, Hegde PS, Mellman I, Chen DS, Hodi FS. Predictive correlates of response to the anti-PD-L1 antibody MPDL3280A in cancer patients. Nature. 2014;515:563-7.

27. Tokito T, Azuma K, Kawahara A, Ishii H, Yamada K, Matsuo N, Kinoshita T, Mizukami N, Ono H, Kage M, Hoshino T. Predictive relevance of PD-L1 expression combined with CD8+ TIL density in stage III non-small cell lung cancer patients receiving concurrent chemoradiotherapy. Eur J Cancer. 2016:55:7-14.

28. Li T, Fan J, Wang B, Traugh N, Chen Q, Liu JS, Li B, Liu XS. TIMER: A web server for comprehensive analysis of tumor-infiltrating Immune cells. Cancer Res. 2017;77:e108-10.

29. Li B, Severson E, Pignon JC, Zhao H, Li T, Novak J, Jiang P, Shen H, Aster JC, Rodig S, Signoretti S, Liu JS, Liu XS. Comprehensive analyses 
of tumor immunity: implications for cancer immunotherapy. Genome Biol. 2016;17:174.

30. Cancer Genome Atlas Research N. Comprehensive genomic characterization of squamous cell lung cancers. Nature. 2012;489:519-25.

31. Zhang XC, Wang J, Shao GG, Wang Q, Qu X, Wang B, Moy C, Fan Y, Albertyn Z, Huang X, Zhang J, Qiu Y, Platero S, Lorenzi MV, Zudaire E, Yang J, Cheng Y, Xu L, Wu YL. Comprehensive genomic and immunological characterization of Chinese non-small cell lung cancer patients. Nat Commun. 2019;10:1772.

32. Yu H, Chen Z, Ballman KV, Watson MA, Govindan R, Lanc I, Beer DG, Bueno R, Chirieac LR, Chui MH, Chen G, Franklin WA, Gandara DR, Genova C, Brovsky KA, Joshi MM, Merrick DT, Richards WG, Rivard CJ, Harpole DH, Tsao MS, van Bokhoven A, Shepherd FA, Hirsch FR. Correlation of PD-L1 expression with tumor mutation burden and gene signatures for prognosis in early-stage squamous cell lung carcinoma. J Thorac Oncol. 2018.

33. Teng MW, Ngiow SF, Ribas A, Smyth MJ. Classifying cancers based on T-cell infiltration and PD-L1. Cancer Res. 2015;75:2139-45.

34. Choi M, Kadara H, Zhang J, Parra ER, Rodriquez-Canales J, Gaffney SG, Zhao Z, Behrens C, Fujimoto J, Chow C, Kim K, Kalhor N, Moran C, Rimm D, Swisher S, Gibbons DL, Heymach J, Kaftan E, Townsend JP, Lynch TJ, Schlessinger J, Lee J, Lifton RP, Herbst RS, Wistuba II. Mutation profiles in early-stage lung squamous cell carcinoma with clinical follow-up and correlation with markers of immune function. Ann Oncol. 2017:28:83-9.

35. Okamoto T, Takada K, Sato S, Toyokawa G, Tagawa T, Shoji F, Nakanishi R, Oki E, Koike T, Nagahashi M, Ichikawa H, Shimada Y, Watanabe S, Kikuchi T, Akazawa K, Lyle S, Takabe K, Okuda S, Sugio K, Wakai T, Tsuchida M, Maehara Y. Clinical and genetic implications of mutation burden in squamous cell carcinoma of the lung. Ann Surg Oncol. 2018;25:1564-71.

36. Alexandrov LB, Nik-Zainal S, Wedge DC, Aparicio SA, Behjati S, Biankin AV, Bignell GR, Bolli N, Borg A, Borresen-Dale AL, Boyault S, Burkhardt B, Butler AP, Caldas C, Davies HR, Desmedt C, Eils R, Eyfjord JE, Foekens JA, Greaves M, Hosoda F, Hutter B, llicic T, Imbeaud S, Imielinski M, Jager N, Jones DT, Jones D, Knappskog S, Kool M, Lakhani SR, Lopez-Otin C, Martin S, Munshi NC, Nakamura H, Northcott PA, Pajic M, Papaemmanuil E, Paradiso A, Pearson JV, Puente XS, Raine K, Ramakrishna M, Richardson AL, Richter J, Rosenstiel P, Schlesner M, Schumacher TN, Span PN, Teague JW, Totoki Y, Tutt AN, Valdes-Mas R, van Buuren MM. van 't Veer L, Vincent-Salomon A, Waddell N, Yates LR, Australian Pancreatic Cancer Genome I, Consortium IBC, Consortium IM-S, PedBrain I, Zucman-Rossi J, Futreal PA, McDermott U, Lichter P, Meyerson M, Grimmond SM, Siebert R, Campo E, Shibata T, Pfister SM, Campbell PJ, Stratton MR. Signatures of mutational processes in human cancer. Nature. 2013;500:415-21.

37. Vogelstein B, Papadopoulos N, Velculescu VE, Zhou S, Diaz LA Jr, Kinzler KW. Cancer genome landscapes. Science. 2013;339:1546-58

38. Davoli T, Uno H, Wooten EC, Elledge SJ. Tumor aneuploidy correlates with markers of immune evasion and with reduced response to immunotherapy. Science. 2017;355.

39. Brahmer JR. Immune checkpoint blockade: the hope for immunotherapy as a treatment of lung cancer? Semin Oncol. 2014;41:126-32.

40. Ahmed SM, Luo L, Namani A, Wang XJ, Tang X. Nrf2 signaling pathway: pivotal roles in inflammation. Biochim Biophys Acta Mol Basis Dis. 2017; 1863:585-97.

41. Frank R, Scheffler M, Merkelbach-Bruse S, Ihle MA, Kron A, Rauer M, Ueckeroth F, Konig K, Michels S, Fischer R, Eisert A, Fassunke J, Heydt C, Serke M, Ko YD, Gerigk U, Geist T, Kaminsky B, Heukamp LC, Clement-Ziza M, Buttner R, Wolf J. Clinical and pathological characteristics of KEAP1- and NFE2L2-mutated non-small cell lung carcinoma (NSCLC). Clin Cancer Res. 2018;24:3087-96.

42. Owada-Ozaki Y, Muto S, Takagi H, Inoue T, Watanabe Y, Fukuhara M, Yamaura T, Okabe N, Matsumura Y, Hasegawa T, Ohsugi J, Hoshino M, Shio Y, Nanamiya H, Imai Jl, Isogai T, Watanabe S, Suzuki H. Prognostic impact of tumor mutation burden in patients with completely resected non-small cell lung cancer: brief report. J Thorac Oncol. 2018;13:1217-21.

43. Brambilla E, Le Teuff G, Marguet S, Lantuejoul S, Dunant A, Graziano S, Pirker R, Douillard JY, Le Chevalier T, Filipits M, Rosell R, Kratzke R, Popper H, Soria JC, Shepherd FA, Seymour L, Tsao MS. Prognostic effect of tumor lymphocytic infiltration in resectable non-small-cell lung cancer. J Clin Oncol. 2016:34:1223-30.

44. Chen YP, Zhang Y, Lv JW, Li YQ, Wang YQ, He QM, Yang XJ, Sun Y, Mao YP, Yun JP, Liu N, Ma J. Genomic analysis of tumor microenvironment immune types across 14 solid cancer types: immunotherapeutic implications. Theranostics. 2017;7:3585-94.

\section{Ready to submit your research? Choose BMC and benefit from:}

- fast, convenient online submission

- thorough peer review by experienced researchers in your field

- rapid publication on acceptance

- support for research data, including large and complex data types

- gold Open Access which fosters wider collaboration and increased citations

- maximum visibility for your research: over $100 \mathrm{M}$ website views per year

At BMC, research is always in progress.

Learn more biomedcentral.com/submissions 